\title{
A LIVRE EXPRESSÃO NA PEDAGOGIA FREINET
}

\author{
LA LIBRE EXPRESIÓN EN LA PEDAGOGÍA FREINET
}

THE FREE EXPRESSION IN FREINET'S PEDAGOGY

Marta SCARPATO ${ }^{1}$

RESUMO: A livre expressão é um aspecto que merece um olhar especial na Pedagogia criada pelo educador Célestin Freinet que enfatiza que o ser humano tem necessidade e desejo de se comunicar e se expressar nas diferentes linguagens: desenho, escrita, fala e pelo corpo. $\mathrm{O}$ incentivo à livre expressão dos alunos na pedagogia Freinet ocorre em todas as suas Técnicas de ensino: Jornal Escolar, roda da conversa, Imprensa escolar, Correspondência interescolar, aula-passeio, entre outras. Diante disso faz-se necessário uma reflexão sobre a importância da livre expressão, do movimento corporal na educação escolar para podermos explorar mais as diferentes formas de linguagem e propiciarmos uma educação que foque o desenvolvimento integral dos alunos.

PALAVRAS-CHAVE: Livre expressão. Pedagogia Freinet. Educação escolar.

RESUMEN: La libertad de expresión es un aspecto que merece una mirada especial en la pedagogía Freinet creado por Célestin educador que hace hincapié en que el ser humano tiene la necesidad y el deseo de comunicarse y expresarse en diferentes idiomas: dibujo, escritura, habla y cuerpo. El incentivo a la libre expresión de los estudiantes de pedagogía Freinet se produce en todas sus técnicas de enseñanza: Colegio Oficial, conversación rueda de Prensa Escuela, interescolar correspondencia, clase de tracción, entre otros. Por lo tanto, es necesario reflexionar sobre la importancia de la libertad de expresión, el movimiento del cuerpo en la educación escolar con el fin de explorar más a fondo las diferentes formas de lenguaje y propiciarmos una educación que se centra en el desarrollo integral de los estudiantes.

PALAVRAS CLAVE: Livre expressão. Pedagogia Freinet. Educação escolar.

SUMMARY: Free expression is an aspect of education that deserves special consideration in the pedagogy created by the educator Célestin Freinet, who emphasizes that human beings have a need and a desire to communicate and express themselves in different forms of language: drawing, writing, speaking and using the body. The encouragement to the free expression of students in Freinet's pedagogy occurs in all of his teaching techniques: school newspaper, conversation circle, school press, interscholastic correspondence/interschool communication, field trips, among others. Faced with this, it is necessary to reflect on the dimension of expression, the

${ }^{1}$ Doutora em Educação pela PUC/SP. Professora Titular da Universidade Paulista, professora convidada da Pós-graduação Lato Sensu da PUC/SP. Avaliadora do INEP/MEC. Email: martascarpato@uol.com.br. 
body movement/language in school education so that we can better explore the different forms of language and provide an education that focuses on the integral development of the students.

KEYWORDS: Free expression. Freinet pedagogy. School education.

\section{Introdução}

$\mathrm{Na}$ Pedagogia Freinet muitos aspectos merecem um destaque especial, a livre expressão é um deles. Nesta proposta pedagógica há o incentivo ao impulso criador porque Freinet acreditou profundamente na capacidade criadora do ser humano. Mas antes de me aprofundar nesta temática apresento como esta pedagogia gerou uma grande influência em minha trajetória.

Freinet foi um dos teóricos que contribuiu com a minha formação acadêmica, na construção da minha identidade docente e consequentemente em minha atuação desde que quando era professora da educação básica até hoje como professora universitária.

Conheci sua Pedagogia na década de 90 quando ainda cursava Pedagogia na PUC/SP e de imediato me identifiquei com os princípios pedagógicos inovadores. $\mathrm{Na}$ época me filiei ao Núcleo Freinet da Cidade de São Paulo, o qual era coordenado por Rosa Maria Sampaio (1989) e Maria Lucia Santos (1991) e convivi com muitos educadores freinetianos de vários Estados do Brasil e também de outros países.

Em 1996 - ano do Centenário no Nascimento do Freinet, cursando mestrado (Scarpato, 1996) na Unicamp ganhei uma bolsa de estudos e fui coletar dados para minha pesquisa. Estagiei na École Martinon em Bordeaux, École Freinet em Vence e participei da Conferência do Centenário e Encontro Internacional de Crianças e Adolescentes que estudavam em escolas freinetianas e praticaram a Correspondência Interescolar, em Paris. Constatei a liberdade de expressão, em todos os momentos de minha estadia seja nas escolas, nas universidades, nos Seminários e entre os pesquisadores freinetianos de todo o mundo.

Nas escolas estagiadas verfiquei a livre expressão nas mais variadas formas de manifestação: corporal, verbal, nas artes: pintura, dança, poesia, entre outras. Nas classes estagiadas imperavam um clima harmonioso, democrático, ético prazeroso, as aulas sempre transmitiam um ar prazeroso, de aprendizagem, curiosidade. Percebia que 
os alunos não estavam entediados, sentados o tempo todo, ouvindo o professor, mas estavam envolvidos com o que faziam, querendo aprender em grupo, descobrir coisas novas.

Acredito que a aula deve ser considerada um encontro para aprender, refletir e crescer com o outro, permitindo que os alunos exponham seus conhecimentos de mundo, para que se sintam acolhidos, podendo se expressar de diferentes modos, linguagens e desenvolver suas várias habilidades. (Scarpato, 2012). E foi extamente assim que constatei as aulas.

Para que o aluno queira aprender é necessário estímulo, motivação e isso ocorre, quando suas necessidades vitais são satisfeitas. Segundo Freinet (apud Sampaio, 1989, p.177), as necessidades vitais são: criar, inata em todo ser humano: expressar-se, comunicar-se, viver em grupo, ter sucesso, de agir-descobrir e organizar-se. Se o aluno puder satisfazer essas necessidades, sentir-se-á mais animado, envolvido, com interesse, querendo produzir, construir seu conhecimento e autonomia.

Uma sala de aula freinetiana é repleta de pinturas, desenhos e confecções dos alunos. O projeto pedagógico não visa torná-los escritores ou artistas, mas possibilitar que se manifestem livremente, sem modelos únicos ou impostos.

Élise Freinet, esposa de Freinet e artista, tornou- se sua parceira no entusiasmo e estímulo às expressões artísticas dos alunos. Em 1955, organizou uma exposição de desenhos livres de seus alunos de Vence, que deixa Pablo Picasso emocionado pela exuberância e qualidade de criação.

No Encontro das Crianças que participei em Paris (1996), observei os alunos das escolas Freinet apresentando músicas, danças, poesias das culturas dos seus países. E, nas RIDEF (Encontro Internacional dos Educadores Freinet), que ocorrem de 2 em 2 anos, os educadores e educandos sempre demonstram as manifestações artísticas de suas culturas.

$\mathrm{Na}$ Pedagogia Freinet, as diferentes manifestações artísticas são vistas como a livre expressão da criança, como um meio de demonstrar o que sente, vive e aprende. ... Para só falar da música: a criança possui o sentido musical muito antes de um pedagogo lho inculcar; canta com naturalidade... (Freinet apud Freinet, É, 1978, p. 404)

\section{Livre expressão}


O termo liberdade de expressão, segundo a concepção freinetiana, pontua que o homem tem necessidade e desejo de se comunicar, de se expressar nas diferentes linguagens: desenho, escrita, fala e pelo corpo. Apesar de que "expressão livre" pode ser um termo inadequado, porque qualquer forma de expressão sofre influências do meio, e Freinet tinha consciência de que os fatores externos interferiam na vida e na formação do ser humano.

Viver livremente só adquire sentido, na nossa sociedade burguesa, para aqueles poucos que podem preocupar-se exclusivamente com seus prazeres ...Trabalhar livremente são duas palavras que, nesta sociedade, aparecem como completamente antagônicas. Freinet (apud Oliveira, 1995, p.147)

Para Freinet, liberdade significa cada homem construir sua concepção de mundo com respeito mútuo, expressando seu ponto de vista, que interferirão nos fatos cotidianos da vida pessoal e do grupo, com discernimento, livre de imposições e incompreensões.

A criança, em sua espontaneidade sempre é criativa e a escola precisa dar-lhe oportunidade de expor, de maneira livre, seus pensamentos, sonhos e alegrias, por meio do desenho, textos livres, pintura, canto, teatro, trabalhos manuais. Freinet sempre salientou que podemos conhecer os alunos por meio de suas livre expressões.

A livre expressão facilita a criatividade da criança no desenho, na música, no teatro, extensões naturais da atividade infantil, progressivamente responsável por seus comportamentos afetivos, intelectuais e culturais. Freinet, É (1979, p.31)

\section{A livre expressão e as Técnicas Freinet}

Freinet não propôs um método de ensino mas técnicas pedagógicas para trazer à sala de aula o interesse, a alegria, a cooperação, possibilitando a livre expressão, a pesquisa e o tateamento experimental sempre enfatizando a cooperação dos alunos.

Suas Técnicas foram elaboradas no início do século XX, num contexto bastante diferente do atual. Porém, elas podem e devem ser adaptadas em qualquer época, para evitar ... a esclerose das Técnicas Freinet (Freinet, 1975, p.167): 
Uma de suas primeiras Técnicas, a aula-passeio, se deve à situação de sua classe em Bar sur Loup: pequena, mal ventilada, escura, dificultava sua respiração, deixando os alunos inquietos, com sensação de prisão.

Eles saem. Começam as famosas "aulas-passeio" (curiosa antinomia!) - que vêm, tranqüilamente, negar o disciplinamento forçado dos corpos e das mentes das crianças do povo. Oliveira (1995, p.112)

Um dos objetivos da aulas-passeio era colocar os alunos em contato com o meio externo, para que saíssem das salas, andassem, sentissem o cheiro do lugar olhassem ao vivo, tocassem para descobertas que os motivassem a criação do texto livre, outra Técnica Freinet.

É perceptível o incentivo à livre expressão dos alunos por meio de todas as suas Técnicas: Jornal Escolar, roda da conversa, Imprensa escolar, etc assim como a concepção integral de ser humano que ele tinha.

\section{A livre expressão por meio do corpo}

A liberdade de expressão corporal, permitida numa sala de aula freinetiana, pode ter sido propiciada devido as condições de saúde do Freinet. As lições orais o deixavam cansado, sem fôlego, a sala de aula era mal ventilada, cheirando a mofo que dificultava a respiração. A sua voz não era forte nem seu físico, imponente, o que impedia o domínio da situação, apesar de ter consciência que isso não resolvia o problema educativo.

Talvez Freinet tivesse suportado melhor a acção deplorável da defeituosa instalação escolar e da pobreza, talvez se tivesse adaptado menos mal aos processos tradicionais..., se não tivesse existido o grave problema de uma saúde comprometida. Freinet, Élise (1978, p.22)

Freinet substituiu a prática pedagógica tradicional por uma prática pedagógica que levasse à ação. Acreditava que a escola precisava aceitar e conhecer as experiências do corpo, que não pode ser considerado um esqueleto que se deve treinar pela repetição de movimentos, mas sim com exercícios e atividades prazerosas. 
A criança tem necessidade de andar e saltar: não a podemos condenar a ficar imóvel, porque certamente falharíamos e a prejudicaríamos... Porque a criança tem necessidade de agir, criar e trabalhar, isto é, empregar a sua atividade numa tarefa individual ou socialmente útil.Freinet (1974, p.49)

A criança quer experimentar, correr riscos, subir em árvores, fazer desenhos, descobrir o mundo que a cerca. Deve-se deixá-la viver experiências variadas: cair, sujar as mãos, escorregar, gritar, pintar, etc. Os adultos, ao querer protegê-la, acabam impedindo que desenvolva seus músculos, audácia e curiosidade.

O ser humano já nasce com pré-disposição para a atividade, que, segundo Freinet, é essencial à vida.

A educação por meio do corpo possibilita:

- desenvolver a capacidade perceptiva que permitirá à criança agir sobre o meio que a cerca, o que antigamente ocorria de modo natural. Hoje, por falta de ambientes livres, pequeno espaço das residências, excesso de imobilidade frente à televisão, computador, tablet ocorrem cada vez menos as experiências naturais que desenvolvem as capacidades de ouvir, sentir, tocar, experimentar e olhar.

- desenvolver as capacidades de expressão e comunicação para o autoconhecimento, domínio corporal, adaptação ao meio, bases de uma expressão livre e consciente.

- agir sobre o meio, os seres, o mundo pelas capacidades funcionais: correr, atacar, defender-se, escalar, lançar, e pelas capacidades de motricidade fina.

No Congresso Internacional da Educação Nova, em Nice, 1932, foi reconhido a importância dos materiais e atividades propostos por Maria Montessori: a experiência tateada, porém dentro dos moldes sociais: pôr a mesa, abotoar casacos, medir objetos. Freinet não conseguia imaginar seus alunos espontâneos nos gestos e impulsos, agindo assim. 
As crianças poderão tactear ou experimentar à vontade: enterrar-se no lodo de um fosso e de lá sair, por si próprias; saltar um muro, escalar rochedos, trepar em árvores, fazer festas a um cão, subir um tronco ou montar um cavalo, seguir a charrua, correr atrás das borboletas, apanhar flores, brincar na terra ou à beira de àgua... Tudo lá estaria: exercício dos membros, agilidade do corpo, habilidade e harmonia dos gestos na sua finalidade natural, construção da vida pessoal a partir de um meio real, aquisição de regras de vida justas, susceptíveis de influenciarem todo o comportamento subseqüente. Freinet (1976, p.224)

Para a criança sem áreas verdes e espaços livres, torna-se difícil desenvolver uma educação integral (Scarpato, 2012) O grande desafio para a escola do Terceiro Milênio é este: propiciar espaço e oportunidade para os alunos se expressarem mais livremente, se exercitarem como meio de educar e desenvolverem se integralmente e integradamente.

Nas escolas que estagiei vi a liberdade de expressão corporal, em todos os momentos. Em qualquer proposta pedagógica o movimento em sala de aula é "proibido", inviável pela distribuição das carteiras, e, muitas vezes, só pode acontecer com a permissão do professor, mas nas salas Freinet "é obrigatório", fundamental que ocorra porque o aluno precisa se mover para realizar suas tarefas, para procurar os materiais que vai utilizar.

Sem o movimento não há aprendizagem, e o mais interessante é que os alunos, durante todo o período escolar realizam várias atividades. Levantam da carteira, pegam o ábaco, vão ao canto da biblioteca e escolhem um livro, sentam ou deitam-se, enfim, escolhem a posição mais confortável e lêem. Tudo na maior naturalidade possível, realmente, como deve ser o processo de aprendizagem.

É claro que a proposta pedagógica freinetiana possibilita essa ação, pela arquitetura da sala de aula em cantos e também pelas Técnicas Freinet.

Esta liberdade de ação e de movimento não tira a concentração e interesse dos alunos. Nas classes Freinet, reina o silêncio, a concentração, os alunos realmente estão envolvidos com o que estão fazendo. O professor não precisa pedir, a todo o momento, para fazer silêncio, para ficar em seus lugares, como numa classe Tradicional.

Infeliz educação a que pretende, pela explicação teórica, fazer crer aos indivíduos que podem ter acesso ao conhecimento pelo conhecimento e não pela experiência. Produziria apenas doentes do corpo e do espírito, falsos intelectuais inadaptados, homens incompletos $\mathrm{e}$ impotentes.Freinet (1991, p.42) 
Não via, nas escolas estagiadas, nenhum professor recriminando o aluno por estar sentado de maneira incorreta. E qual a maneira correta de sentar? Incorreto é deixar o aluno horas sentado numa cadeira, que, às vezes, é pequena ou grande demais para seu tamanho.

É necessário que o professor reflita sobre a importância da livre expressão, do movimento na educação escolar para poder explorar mais as diferentes formas de linguagem dos alunos.

\section{Educação Integral na Pedagogia Freinet}

Há anos pesquiso o processo de ensino-aprendizagem numa perspectiva de desenvolvimento integral tanto do aluno quanto do professor. Essa perspectiva integral de desenvolvimento humano engloba os aspectos cognitivos, afetivos, motores e sociais (Scarpato, 2012). É contra a visão fragmentária que permeia o processo de ensinoaprendizagem dos alunos em sala de aula que concebe que o aluno se desenvolve e aprende só pelo cognitivo deixando à margem os outros aspectos.

Quando passamos a ler sobre a Pedagogia Freinet, conhecer sua proposta pedagógica e observar como o processo de ensino-aprendizagem se desenrola nas escolas e classes freinetianas, nos faz ter certeza que Freinet sempre se preocupou com a visão integral do aluno onde a educação deve ser global, não apenas focando um aspecto do desenvolvimento humano.

\section{Referências}

FREINET, C. As técnicas Freinet da escola moderna. $2^{\mathrm{a}}$ ed. Lisboa: Estampa, 1975.

FREINET, C. Para uma escola do povo. São Paulo: Martins Fontes, 1996.

FREINET, C. Conselho aos pais. $2^{0}$ ed. Lisboa: Ed. Estampa, 1974.

FREINET, C. O jornal escolar. $2^{0}$ ed. Lisboa: Ed. Estampa, 1974.

FREINET, C. Ensaio de psicologia sensível I. Lisboa: Ed. Presença, 1976.

FREINET, C. Pedagogia do bom senso. 30. ed. São Paulo: Martins Fontes, 1991. 
FREINET, C \& SALENGROS, R. Modernizar a escola. Lisboa: Dinalivro, 1977.

FREINET, É. Nascimento de uma pedagogia popular: métodos Freinet. Lisboa: Estampa, 1978.

OLIVEIRA, A. M. M. Célestin Freinet: raízes sociais e políticas de uma proposta pedagógica. Rio de Janeiro: Papéis e Cópias de Botafogo, 1995.

SAMPAIO, R. M. W. F. Freinet: evolução histórica e atualidades. São Paulo: Scipione, 1989.

SANTOS, M. L. A construção de um projeto educativo à luz dos princípios da Pedagogia Freinet. PUC/SP, 1996 (mesa redonda-não publicado)

SCARPATO, M. T. O corpo cria, descobre e dança com Laban e Freinet. Dissertação de mestrado. Campinas: Faculdade de Educação Física/ UNICAMP, 1999.

SCARPATO, M. T. Didática e desenvolvimento integral. São Paulo: Avercamp, 2012.

\section{Como referenciar este artigo}

SCARPATO, Marta. A livre expressão na Pedagogia Freinet. Revista IberoAmericana de Estudos em Educação, Araraquara, v. 12, n. esp. 1, p.620-628, 2017. Disponível em: <http://dx.doi.org/10.21723/riaee.v12.n.esp.1.2017.9667>. E-ISSN: 1982-5587.

Submetido em: 07/04/2017

Aprovado em: 09/04/2017 